\title{
RESÍDUO DA EXTRAÇÃO DE PRÓPOLIS MARROM NA DIETA DE RUMINANTES: DIGESTIBILIDADE E PRODUÇÃO DE GÁS IN VITRO
}

\author{
RESIDUE FROM EXTRACTION OF BROWN PROPOLIS IN THE DIET TO RUMINANTS: \\ IN VITRO DIGESTIBILITY AND GAS PRODUCTION
}

\author{
Heimbach, N.S. ${ }^{1 A} ;$ Ítavo, C.C.B.F. ${ }^{1 *}$; Ítavo, L.C.V. ${ }^{2 A} ;$ Franco, G.L. ${ }^{1 B}$; Leal, C.R.B. ${ }^{1 C} ;$ Leal, E.S. $^{2}$; \\ Silva, P.C.G. ${ }^{1{ }^{D} ;}$ Rezende, L.C. $^{1 \mathrm{E}}$ e Silva, J.A. ${ }^{1 F}$ \\ ${ }^{1}$ Faculdade de Medicina Veterinária e Zootecnia. Universidade Federal de Mato Grosso Sul-FAMEZ/ \\ UFMS. Campo Grande, MS. Brasil. “camila.itavo@ufms.br; Anat_heimbach@hotmail.com; \\ Bgumercindo.franco@ufms.br; ${ }^{\circ}$ cassia.leal@ufms.br; Dcarolinigonçalves@zootenista.com.br; \\ Eleticiarezendel5@hotmail.com; Fjonilsonsilva@zootecnista.com.br \\ ${ }^{2}$ Programa de Pós-Graduação em Ciências Ambientais e Sustentabilidade Agropecuária-UCDB. Campo \\ Grande, MS. Brasil. Aitavo@ucdb.br
}

\section{Palavras chave adicionais}

Aditivo.

\section{RESUMO}

Objetivou-se avaliar o efeito de diferentes níveis de inclusão do resíduo da extração de própolis marrom na dieta de ruminantes, por meio de medidas de digestibilidade e produção de gás. Foram avaliados cinco níveis de inclusão da própolis marrom sobre a digestibilidade in vitro dos nutrientes, sob incubação de 72 horas (sem e com pepsina, consideradas digestão ruminal e total, respectivamente), e produção de gás in vitro. Como substrato foi utilizado feno de capim Tifton (Cynodon) e concentrado à base de farelo de soja e milho moído, com relação volumoso concentrado de 50:50, com base na matéria seca. Dois inóculos ruminais (oriundos de bovinos e ovinos) foram utilizados. Os tratamentos foram distribuídos em um delineamento inteiramente casualizado, com inclusão de 4 níveis de resíduo da extração de própolis marrom $(5,10,15$ e $20 \mathrm{~g}$ de resíduo $/ \mathrm{kg}$ MS). O resíduo da extração de própolis apresentou efeito sobre a digestibilidade ruminal in vitro da matéria seca e fibra em detergente neutro, e a digestibilidade total in vitro também apresentou diferença significativa para digestibilidade da matéria seca, proteína bruta, fibra em detergente neutro, fibra em detergente ácido. O melhor nível de inclusão para digestibilidade total in vitro de 13,88 g de resíduo do extrato de própolis/kg MS. Enquanto que para a produção de gás, o melhor

\section{AditTIONAL KEYWORDS \\ Aditive.}

nível de inclusão in vitro do resíduo da extração de própolis para bovinos foi de $8,52 \mathrm{~g} / \mathrm{kg} \mathrm{MS}$ e para ovinos foi $5,53 \mathrm{~g} / \mathrm{kg} \mathrm{MS}$.

\section{SUMMARY}

The objective of this work was to assess the effect of the different inclusion levels of residue from extraction of propolis in the ruminant diet, using the digestibility and gas production measures. Were evaluated five inclusion levels of brown propolis about the in vitro nutrient digestibility with 72 hours of the incubation (with and without pepsin, considered ruminal and total rumination, respectively), and in vitro gas production. Tifton hay (Cynodon) was utilized as substrate and the concentrate was made from the soybean meal and corn, with relation roughage:concentrate around 50:50, based on dry matter. Two ruminal inoculums (from cattle and sheep) were utilized. The treatments were distributed in completely randomized design, with inclusion of the four levels of residue from extraction of propolis $(5,10,15$ and $20 \mathrm{~g} / \mathrm{kg} \mathrm{DM})$. The inclusion of residue from extraction of propolis had effect on in vitro ruminal digestibility for dry matter and neutral detergent fiber, and total digestibility in vitro had significative diference for dry matter digestibility, 


\section{HEIMBACH, ÍTAVO, ÍTAVO, FRANCO, LEAL, LEAL, SILVA, REZENDE E SILVA}

crude protein, neutral detergent fiber and acid detergent fiber. The best level of inclusion for total digestibility in vitro is $13.88 \mathrm{~g}$ of residue from extraction of propolis/kg DM. While for gas production, the best level in vitro of residue from extraction of propolis for cattle was $8.52 \mathrm{~g} / \mathrm{kg} \mathrm{DM}$ and for sheep was $5.53 \mathrm{~g} / \mathrm{kg} \mathrm{DM}$.

\section{INTRODUÇÃO}

O uso de aditivos na dieta de ruminantes tem como objetivo a melhora do desempenho animal e possível redução da poluição ambiental, por meio da atenuação das perdas por amônia e metano, dentre os quais se destacam os ionóforos (Lana et al., 2007).

Ionóforos reduzem o crescimento de cepas ruminais Gram-positivas, o que resulta em mudanças no padrão de fermentação com redução da relação acetato:propionato, íons $\mathrm{H}^{+}$, metano e amônia (Russel e Strobel, 1989), proporcionando melhor aproveitamento dos nutrientes e eficiência digestiva. No entanto, há certa restrição quanto ao uso de ionóforos por parte de alguns mercados consumidores de produtos de origem animal.

Desse modo, produtos alternativos têm sido testados na alimentação de ruminantes, e a própolis mostra-se como uma alternativa (Ítavo et al., 2011), pois se trata de um produto natural com ação semelhante a dos ionóforos. De acordo Mirzoeva et al. (1997), a própolis apresenta ação bacteriostática sobre cepas bacterianas, principalmente as Gram-positivas.

Na obtenção do extrato de própolis, forma mais utilizada na utilização da própolis, obtém-se $10 \%$ de extrato de própolis, enquanto os $90 \%$ residuais são descartados. Há pouco tempo, pesquisas têm sido feitas sobre a utilização do resíduo da extração de própolis para a aplicação na produção animal.

Heimbach et al. (2009) estudaram o efeito do resíduo da extração de própolis verde e marrom in vitro, pelo método de contagem bacteriana total, e encontraram ação antibacteriana do resíduo da extração de própolis verde e marrom para Escherichia coli e inibição do crescimento de Staphylococcus aureus do resíduo da extração de própolis verde.

Esteves (2012) avaliou o efeito do resíduo da extração da própolis marrom na dieta de cordeiros em confinamento e verificou que o aditivo não influenciou a digestibilidade dos nutrientes (matéria seca, matéria orgânica, proteína bruta, fibra em detergente ácido, carboidratos totais e carboidratos não fibrosos), ao passo que houve diminuição da digestibilidade do extrato etéreo.

Nesse contexto, objetivou-se avaliar diferentes níveis de inclusão do resíduo da extração da própolis marrom, por meio das técnicas de digestibilidade e produção de gás in vitro.

\section{MATERIALE MÉTODOS}

O experimento foi conduzido no Setor de Ovinocultura da Universidade Federal de Mato Grosso do Sul(UFMS) e no Laboratório de Biotecnologia Aplicada à Nutrição Animal da Universidade Católica Dom Bosco, em Campo Grande, Mato Grosso do Sul, Brasil. O protocolo experimental foi aprovado, protocolo n ${ }^{\circ}$ 260/2010, pela Comissão de Ética no uso dos animais da UFMS.

\section{PRÓPOLIS}

A própolis marrom utilizada foi proveniente de pastagem apícola de alecrim-docampo (Baccharis dracunculifolia) e de assa-peixe (Vernonia polyanthes). Para obtenção do extrato de própolis, foram utilizados $30 \mathrm{~g}$ de própolis marrom bruta triturada em moinho de facas tipo Wiley com peneira de crivos de $5 \mathrm{~mm}$, adicionada a 100 $\mathrm{mL}$ de solução etanólica $(70 \mathrm{v} / \mathrm{v})$ de álcool de cereais, armazenada ao abrigo de luz por um período de 10 dias para extração (Stradiotti Jr. et al., 2004b). No processo de extração, após filtragem foi obtido o resíduo da extração de própolis marrom.

A análise da composição química do resíduo da extração de própolis, teores de 


\section{RESÍDUO DA EXTRAÇÃO DE PRÓPOLIS MARROM NA DIETA DE RUMINANTES}

umidade, matéria mineral, resíduo insolúvel em metanol, cera, resíduo seco (sólidos solúveis em metanol), flavonóides e fenóis totais (tabela I), foram feitas seguindo metodologia de Funari e Ferro (2006).

\section{DiETAS}

Para determinação da composição da dieta, amostras de feno e concentrado foram pré-secas em estufa de ventilação forçada de ar, a $55^{\circ} \mathrm{C}$ por 96 horas, e trituradas em moinho de facas dotado de peneira com crivos de $1 \mathrm{~mm}$. Na determinação de matéria seca (MS) e proteína bruta (PB), as análises foram realizadas de acordo com a AOAC (2000), pelos métodos 930.15, 976.05, respectivamente, e da fibra em detergente neutro (FDN) e fibra em detergente ácido (FDA), o método utilizado foi segundo Goering e Van Soest (1970), sem o uso de sulfito e amilase termoestável.

Os substratos utilizados foram feno de capim-Tifton (Cynodon sp.) e concentrado, a base de farelo de soja e milho moído, em uma relação volumoso:concentrado 50:50. A composição química da dieta foi igual a: $981,8 \mathrm{~g} / \mathrm{kg}$ de MS, 151,5 g PB/kg de MS, 598, $1 \mathrm{~g} \mathrm{FDN} / \mathrm{kg}$ de MS, 223,6 g FDA/kg de MS e 374,5 g Hemicelulose/kg de MS.

Foram utilizados 4 níveis de inclusão do resíduo da extração de própolis marrom e um controle (sem adição do resíduo): 0 - sem adição de resíduo da extração de própolis marrom, 5 - 5 g resíduo/kg MS; $10-10 \mathrm{~g}$ resíduo/kg MS; 15 - 15 g resíduo/kg MS; 20 - $20 \mathrm{~g}$ resíduo/kg MS da dieta.

\section{ENSAIO 1 - DigESTIBILIDADE IN VITRO}

Foram utilizadas como doadoras de líquido ruminal, duas vacas com cânula implantada no rúmen.

O primeiro ensaio foi realizado com 72 horas de incubação contínua (digestibilidade ruminal) e o segundo, com incubação de 72 horas, com adição de pepsina às 48 horas de incubação (digestibilidade total) de acordo com metodologia de Tilley e Terry (1963). Nos dois ensaios foram utilizados
Tabela I. Composição do resíduo da extração da própolis marrom (REPM). (Composition of residue from brown própolis extraction).

\begin{tabular}{lc}
\hline & REPM \\
\hline Cinzas (g/kg MS) & 50,31 \\
Proteína bruta (g/kg MS) & 145,7 \\
Extrato etéreo (g/kg MS) & 432,7 \\
Perda por dessecação (g/kg) & 163,59 \\
Resíduo insolúvel em metanol (g/kg MS) & 887,86 \\
Cera (g/kg MS) & 74,27 \\
Resíduo seco (g/kg MS) & 17,78 \\
Fenóis totais (mg/g RS) & 0,24 \\
Flavonóides totais (mg/g RS) & 0,35 \\
\hline
\end{tabular}

$\mathrm{MS}=$ matéria seca; $\mathrm{RS}=$ resíduo seco.

1600 mL de solução tampão de McDougall (saliva artificial) e $400 \mathrm{~mL}$ de líquido ruminal.

As análises foram realizadas com a pesagem de $20 \mathrm{mg}$ de amostra/ $\mathrm{cm}^{2} \mathrm{em}$ saquinhos de TNT 100 4x5 cm em triplicata, selados, previamente lavados em acetona, secos e pesados. Pesou-se 0,5 g da dieta em cada saquinho, na proporção de volumoso:concentrado 50:50, e 0,0025 g de resíduo da extração de própolis (5), 0,005 g de resíduo da extração de própolis (10), $0,0075 \mathrm{~g}$ de resíduo da extração de própolis (15) e $0,01 \mathrm{~g}$ de resíduo da extração de própolis (20). Depois da pesagem das amostras e selagem dos saquinhos, os mesmos foram colocados na incubadora in vitro para teste de degradabilidade, modelo MA 443 (Marconi®), com simulação do ambiente ruminal. Antes do fechamento dos frascos, colocou-se saliva artificial e líquido ruminal e depois de fechado o frasco, injetou-se $\mathrm{CO}_{2}$, para melhor simulação do ambiente ruminal. Em cada frasco havia nove repetições do mesmo tratamento, além dos saquinhos considerados brancos (sem amostra). Na digestão total, após 48 horas de incubação, foi adicionada a enzima pepsina ( $8 \mathrm{~g}$ de pepsina e $40 \mathrm{~mL}$ de $\mathrm{HCl}$ em cada frasco), permanecendo a incubação por mais 24 horas, e na digestão ruminal, 


\section{HEIMBACH, ÍTAVO, ÍTAVO, FRANCO, LEAL, LEAL, SILVA, REZENDE E SILVA}

seguindo-se a incubação direta por $72 \mathrm{~h}$.

\section{ENSAIO 2 - PRODUÇÃO DE GÁS IN VITRO}

Para análise da produção de gás, foram utilizados como doadores de líquido ruminal, duas vacas e três ovinos com cânula implantada no rúmen.

Foram feitas duas baterias no aparelho, uma com líquido ruminal de bovinos e outra de ovinos. Pesou-se 0,5 g da dieta, em duplicata, incubados com saliva artificial (100 mL em cada frasco) e líquido ruminal (25 $\mathrm{mL}$ em cada frasco). Antes do fechamento dos módulos do aparelho, injetou-se $\mathrm{CO}_{2}$, para melhor simulação do ambiente ruminal. A cinética da digestão foi avaliada nas 72 horas de incubação, por intermédio da produção de gás in vitro no processo fermentativo de cada alimento por meio do sistema computadorizado sem fio, dotado de transdutor de pressão, com comunicação feita por rádio freqüência (ANKOMßRF Gas production system). Os dados de pressão, em psi, foram coletados a cada 1 minuto, e foram transformados para $\mathrm{mL}$ de gás/100 mg de matéria seca. Os valores de degradabilidade, correspondentes às diferentes frações analisadas, foram obtidos segundo modelo logístico bicompartimental proposto por Pell e Schofield (1994):

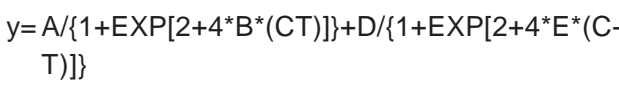

A e $D=$ volume de gás $(\mathrm{mL})$ das frações de degradação rápida (açúcares solúveis e amido) e lenta (celulose e hemicelulose), respectivamente;

$B$ e $E=$ taxas de degradações das frações de digestão rápida e lenta $(\% / h)$, respectivamente;

$\mathrm{C}=$ tempo de colonização das bactérias (horas).

\section{AnÁlises estatísticAs}

Para digestibilidade in vitro, os tratamentos foram distribuídos em delineamento inteiramente casualizado. Os dados foram avaliados por meio de análises de variância e as médias foram comparadas pelo teste Tukey, com $5 \%$ de significância.

Para a produção de gás in vitro, os parâmetros da cinética da digestão dos alimentos, em função do nível do aditivo, foram analisados sob a forma de coeficiente de variação (CV em \%), em duplicatas por amostras. O delineamento experimental utilizado para comparar os parâmetros da cinética da digestão foi o inteiramente casualizado, com duas repetições por tratamento (5 níveis de inclusão), para cada inóculo ruminal (bovino e ovino).

\section{RESULTADOSEDISCUSSÃO}

\section{ENSAIO 1 - DIGESTIBILIDADE IN VITRO}

$\mathrm{Na}$ digestibilidade ruminal, o melhor nível de inclusão é em torno de $20 \mathrm{~g}$ de resíduo do extrato de própolis/kg MS. A digestibilidade da matéria seca (MS) mostrou um aumento linear, com o aumento do nível de inclusão, maior que $20 \mathrm{~g}$ de resíduo da extração de própolis marrom $/ \mathrm{kg}$ MS, proporcionou melhor digestibilidade (tabela II).

A digestibilidade ruminal da fibra em detergente neutro (FDN) apresentou o mesmo comportamento da digestibilidade da MS, sendo maior $(\mathrm{p}<0,05), 76,70 \%$, para a inclusão de $20 \mathrm{~g}$ de resíduo do extrato de própolis/kg MS. Corroborando com os dados do presente estudo, Silva (2011) estudando a digestibilidade in vitro, encontrou diferenças entre os níveis de inclusão de própolis nas dietas. Houve maior digestibilidade ruminal da FDN (66,75 e $70,25 \%$ ), quando a inclusão foi entre 8,7 e $14,5 \mathrm{~g}$ de própolis marrom bruta/kg MS da dieta, o que se aproxima da digestibilidade ruminal da FDN $(69,48$ e 73,44\%) com inclusão de 5 e $15 \mathrm{~g}$ de resíduo/kg MS, respectivamente.

Não houve diferença significativa para digestibilidade de proteína bruta $(\mathrm{PB})$ e digestibilidade da fibra em detergente ácido 
RESÍDUO DA EXTRAÇÃO DE PRÓPOLIS MARROM NA DIETA DE RUMINANTES

Tabela II. Digestibilidade ruminal in vitro, em função de níveis de inclusão de resíduo da extração da própolis. (Ruminal digestibility in vitro, due to inclusion levels of residue from propolis extraction).

\begin{tabular}{lccccccc}
\hline & \multicolumn{8}{c}{ Resíduo da } & \multicolumn{8}{c}{ extração da própolis marrom (g/kg MS da dieta) } & \multicolumn{2}{c}{ CV } & p \\
& 0 & 5 & 10 & 15 & 20 & $(\%)$ & \\
\hline DIVMS $^{1}$ & 63,95 & 67,09 & 75,37 & 74,05 & 75,58 & 4,69 & 0,00022 \\
DIVPB $^{2}$ & 68,55 & 77,88 & 79,75 & 75,87 & 80,48 & 9,77 & 0,08901 \\
DIVFDN $^{3}$ & 62,12 & 69,48 & 74,14 & 73,44 & 76,60 & 4,27 & 0,04717 \\
DIVFDA $^{4}$ & 60,57 & 54,42 & 62,16 & 59,48 & 65,28 & 6,59 & 0,06623 \\
\hline
\end{tabular}

$\mathrm{DIV}=$ digestibilidade in vitro; $\mathrm{MS}=$ matéria seca; $\mathrm{PB}=$ proteína bruta; $\mathrm{FDN}=$ fibra em detergente neutro; $\mathrm{FDA}=$ fibra em detergente ácido.

${ }^{1} Y=64,9598+0,617930 \times$ resíduo $\left(R^{2}=0,82\right) ;{ }^{2} Y=76,50633 ;{ }^{3} Y=62,4977+1,46372 \times$ resíduo $\left(R^{2}=0,96\right)$; ${ }^{4} Y=60,38275$

(FDA), em função da inclusão de resíduo da extração de própolis marrom na dieta. Também Silva (2011) não encontrou efeito significativo de aditivos alimentares (própolis bruta, extrato de própolis e monensina) sobre a digestibilidade in vivo da matéria seca, proteína bruta, fibra em detergente neutro e fibra em detergente ácido de ovinos confinados, porém, as médias de digestibilidade total da MS, PB, FDN e FDA utilizando o extrato de própolis foram iguais a 73,$46 ; 77,74 ; 65,42$ e $61,98 \%$ respectivamente, as quais se aproximam das médias da digestibilidade ruminal in vitro deste estudo.

$\mathrm{Na}$ digestibilidade total, o melhor nível de inclusão é em torno de 13,88 g do resíduo do extrato de própolis/kg MS. Houve uma melhor digestibilidade da matéria seca (MS), quando adicionou-se 13,94 g de resíduo da extração de própolis/kg MS, como pode ser visualizado na tabela III. A diferença na digestibilidade pode estar relacionada a atividade antimicrobiana do aditivo, especialmente contra bactérias Gram-positivas. Segundo Prado et al. (2010), as diferentes

Tabela III. Digestibilidade total in vitro, em função de níveis de inclusão de resíduo da extração da própolis. (Total digestibility in vitro, due to inclusion levels of residue from propolis extraction).

\begin{tabular}{lccccccc}
\hline & \multicolumn{8}{c}{ Resíduo da extração da própolis marrom (g/kg MS da dieta) } & CV & p \\
& 0 & 5 & 10 & 15 & 20 & $(\%)$ & \\
\hline DIVMS $^{1}$ & 58,71 & 69,51 & 71,42 & 73,47 & 71,29 & 2,53 & 0,00001 \\
DIVPB $^{2}$ & 65,76 & 71,42 & 75,38 & 75,41 & 75,98 & 2,58 & 0,00262 \\
DIVFDN $^{3}$ & 53,09 & 66,38 & 68,47 & 68,34 & 65,60 & 2,76 & 0,00001 \\
DIVFDA $^{4}$ & 53,91 & 63,94 & 67,18 & 67,39 & 67,39 & 3,41 & 0,00001 \\
\hline
\end{tabular}

$\mathrm{DIV}=$ digestibilidade in vitro; $\mathrm{MS}=$ matéria seca; $\mathrm{PB}=$ proteína bruta; $F D N=$ fibra em detergente neutro; $\mathrm{FDA}=$ fibra em detergente ácido.

${ }^{1} Y=59,1230+2,09973 \times$ resíduo $-0,0753190 \times{ }^{2}\left(R^{2}=0,98\right) ;{ }^{2} Y=65,8380+1,30373 \times$ resíduo $-0,0406395$ $\mathrm{x}^{2}\left(\mathrm{R}^{2}=0,99\right) ;{ }^{3} \mathrm{Y}=53,7158+2,56337 \mathrm{x}$ resíduo $-0,1003660 \mathrm{x}^{2}\left(\mathrm{R}^{2}=0,96\right) ;{ }^{4} \mathrm{Y}=54,1522+2,20640 \mathrm{x}$ resíduo $-0,0864540 x^{2}\left(R^{2}=0,99\right)$. 
HEIMBACH, ÍTAVO, ÍTAVO, FRANCO, LEAL, LEAL, SILVA, REZENDE ESILVA

Tabela IV. Parâmetros estimados da produção cumulativa de gases in vitro em líquido ruminal de bovinos, em função de níveis de inclusão de resíduo de própolis. (Estimated parameters of the cumulative gas production in vitro rumen of cattle, due to inclusion levels of propolis residue).

\begin{tabular}{|c|c|c|c|c|c|c|c|}
\hline & \multicolumn{5}{|c|}{ Resíduo da extração da própolis marrom ( $\mathrm{g} / \mathrm{kg}$ MS da dieta) } & \multirow{2}{*}{$\begin{array}{l}\text { CV } \\
(\%)\end{array}$} & \multirow[t]{2}{*}{$\mathrm{p}$} \\
\hline & 0 & 5 & 10 & 15 & 20 & & \\
\hline$A(m L)^{1}$ & 3,94 & 4,75 & 2,25 & 3,74 & 4,38 & 43,30 & 0,10347 \\
\hline$B\left(h^{-1}\right)^{2}$ & 0,9882 & 0,9879 & 0,9876 & 0,9301 & 0,8567 & 19,52 & 0,00661 \\
\hline$C(h)^{3}$ & 1,59 & 1,59 & 1,84 & 3,40 & 4,36 & 36,29 & 0,00998 \\
\hline $\mathrm{D}(\mathrm{mL})^{4}$ & 12,03 & 11,79 & 11,01 & 9,07 & 7,56 & 9,96 & 0,01121 \\
\hline$E\left(h^{-1}\right)^{5}$ & 0,0261 & 0,0256 & 0,0273 & 0,0297 & 0,0293 & 10,59 & 0,00867 \\
\hline$A+D(m L)^{6}$ & 15,81 & 16,89 & 13,46 & 12,22 & 10,32 & 6,03 & 0,00424 \\
\hline
\end{tabular}

$A=$ volume de gás das frações de degradação rápida (açúcares solúveis e amido); $B=$ taxa de degradação das frações de digestão rápida; $\mathrm{C}=$ tempo de colonização das bactérias; $\mathrm{D}=$ volume de gás das frações de degradação lenta (celulose e hemicelulose); $E=$ taxa de degradação das frações de digestão lenta.

${ }^{1} Y=3,81190 ;{ }^{2} Y=0,9852+0,0521096 x$ resíduo $-0,000581269 . n^{2}\left(R^{2}=0,99\right) ;{ }^{3} Y=1,08778+0,146739$ $x$ resíduo $\left(R^{2}=0,85\right) ;{ }^{4} Y=12,6285-0,233397 \times$ resíduo $\left(R^{2}=0,78\right) ;{ }^{5} Y=0,0254969+0,000210522 x$ resíduo $\left(R^{2}=0,82\right) ;{ }^{6} Y=15,8178+4,85597 \times$ resíduo ${ }^{0,5}-2,62703 \times$ resíduo $+0,284909 \times$ resíduo ${ }^{1,5}\left(R^{2}=\right.$ $0,87)$.

concentrações de própolis liberam substâncias flavonoídicas que atuam com maior ou menor intensidade sobre as bactérias Gram-positivas. Essas diferentes concentrações apresentam interferência de ceras e resinas, que impediriam a liberação de substâncias ativas atuantes na digestibilidade da matéria seca.

A digestibilidade total da proteína bruta (PB) teve seu ponto de máximo com a inclusão de 16,04 g de resíduo da extração de própolis marrom $/ \mathrm{kg}$ MS. De outra maneira, a digestibilidade da fibra em detergente ácido (FDA), apresentou sua melhor digestibilidade, bem como a fibra em detergente neutro (FDN), com uma inclusão de $12,76 \mathrm{e}$ $12,77 \mathrm{~g}$ de resíduo da extração de própolis/ kg MS, respectivamente. Também Esteves (2012), não observou influência do uso de resíduo da extração de própolis marrom nos coeficientes de digestibilidade in vivo de nutrientes em cordeiros confinados. Entretanto, Stelzer et al. (2009) não encontraram influência do uso do extrato de própolis na digestibilidade de vacas leiteiras.

\section{ENSAIO 2 - PRODUÇÃO DE GÁS IN VITRO}

Os parâmetros A, B, C, D, E e A+D da cinética de degradação foram influenciados pelos níveis de resíduo da extração da própolis marrom na dieta, para inóculos de bovinos e de ovinos (tabelas IV e V).

De acordo com Schofield et al. (1994), a digestão anaeróbica da celulose e de outros tipos de fibra pelos microrganismos ruminais (Ruminococcus albus, Fibrobacter succinogenes, Ruminococcus flavefaciens), produz $\mathrm{AGV}, \mathrm{CO}_{2}, \mathrm{CH}_{4}$, e traços de $\mathrm{H}_{2}$. Em ambas as situações, in vitro e in vivo, os AGVs reagem com tampão de bicarbonato para liberar $\mathrm{CO}_{2}$, então ocorre produção de gás simultaneamente à digestão de fibra, ou seja, maior degradação ocasiona maior produção de gás.

Para bovinos, encontrou-se o melhor nível de inclusão in vitro de $8,52 \mathrm{~g} / \mathrm{kg}$ MS da dieta para maior produção de gás. A média do volume de gás produzido, independente 


\section{RESÍDUO DA EXTRAÇÃO DE PRÓPOLIS MARROM NA DIETA DE RUMINANTES}

do nível de inclusão foi de $3,81 \mathrm{~mL}$. Observou-se diminuição no volume de gás produzido pela degradação da fração lenta, aliado a um aumento na velocidade de degradação (conforme aumenta-se o nível de inclusão do resíduo). De acordo com Silva e Leão (1979), as bactérias responsáveis pela degradação lenta são digestoras de celulose (celulolíticas), como: $\mathrm{Bu}$ tyrivibrio fibriosolvens, Clostridium Iochheadii, Clostridium longisporum, Cillobacterium cellulosolvens. Dessa maneira, parece ter havido uma tentativa de melhora na degradação, ligado ao fato do resíduo da extração de própolis marrom provavelmente ter inibido algumas das bactérias ruminais. O tempo de colonização (lag time) aumentou conforme aumentou-se o nível de inclusão do resíduo da extração de própolis marrom. $\mathrm{O}$ aumento do nível de inclusão de resíduo da extração de própolis marrom, diminuiu a produção total de gases $(\mathrm{A}+\mathrm{D})$ em bovinos. Com uso de extrato de própolis na avaliação in vitro utilizando líquido ruminal de bovinos, Stradiotti Jr. et al. (2004a), encontraram maior volume final de gases, concomitante com maior degradação de carboidratos, em dieta com menor concentração de extrato de própolis no extrato $(16,7 \%)$ e no tratamento controle, sendo 39,80 e 40,69 mL, respectivamente, enquanto que na maior concentração de própolis no extrato $(66,7 \%)$, houve menor volume total de gás $(22,66 \mathrm{~mL})$.

A ação da própolis sobre a desaminação de aminoácidos e a fermentação ruminal foi avaliada por Stradiotti Jr. et al. (2004b), que encontraram que o extrato de própolis não afetou a proporção dos ácidos acético, propriônico e butírico no total dos ácidos graxos no líquido ruminal, porém aumentou a concentração total de AGVs. A própolis foi eficiente em inibir a atividade de desaminação de aminoácidos pelos microrganismos ruminais (Stradiotti Jr. et al., 2004b).

Para ovinos, a maior quantidade de degradação foi obtida com a inclusão de $5,53 \mathrm{~g} / \mathrm{kg}$, porém para velocidade de degradação dos carboidratos fibrosos, esse nível não é o ideal, e sim uma inclusão de

Tabela V. Parâmetros estimados da produção cumulativa de gases in vitro em líquido ruminal de ovinos, em função de níveis de inclusão de resíduo de própolis. (Estimated parameters of the cumulative gas production in vitro rumen of sheep as a function of inclusion levels of propolis residue).

\begin{tabular}{|c|c|c|c|c|c|c|c|}
\hline & \multicolumn{5}{|c|}{ Resíduo da extração da própolis marrom (g/kg MS da dieta) } & \multirow{2}{*}{$\begin{array}{l}\text { CV } \\
(\%)\end{array}$} & \multirow[t]{2}{*}{ o } \\
\hline & 0 & 5 & 10 & 15 & 20 & & \\
\hline$A(m L)^{1}$ & 2,98 & 4,39 & 6,94 & 3,98 & 4,36 & 62,60 & 0,04209 \\
\hline$B\left(h^{-1}\right)^{2}$ & 0,9435 & 0,8447 & 0,9300 & 0,9132 & 0,8906 & 15,45 & 0,06003 \\
\hline$C(h)^{3}$ & 6,51 & 5,70 & 7,55 & 4,94 & 7,69 & 57,14 & 0,3352 \\
\hline $\mathrm{D}(\mathrm{mL})^{4}$ & 11,10 & 11,52 & 11,24 & 6,00 & 7,29 & 17,88 & 0,00001 \\
\hline$E\left(h^{-1}\right)^{5}$ & 0,0321 & 0,0355 & 0,0433 & 0,0316 & 0,0264 & 27,53 & 0,00253 \\
\hline$A+D(m L)^{6}$ & 14,08 & 15,92 & 18,18 & 9,98 & 11,66 & 24,74 & 0,02586 \\
\hline
\end{tabular}

$A=$ volume de gás das frações de degradação rápida (açúcares solúveis e amido); $B=$ taxa de degradação das frações de digestão rápida; $\mathrm{C}=$ tempo de colonização das bactérias; $\mathrm{D}=$ volume de gás das frações de degradação lenta (celulose e hemicelulose); $E=$ taxa de degradação das frações de digestão lenta.

${ }^{1} Y=3,03152+0,434756 \times$ resíduo $-0,0196866$ x resíduo $\left(R^{2}=0,96\right) ;{ }^{2} Y=0,9033 ;{ }^{3} Y=6,3551 ;{ }^{4} Y=12,0555$ $-0,275985 \times$ resíduo $\left(R^{2}=0,99\right) ;{ }^{5} Y=0,0316920+0,00166955 \times$ resíduo $-0,0000994043 \times$ resíduo ${ }^{2}\left(R^{2}=\right.$ $0,96) ;{ }^{6} Y=14,7540+0,291373 \times$ resíduo $-0,0263475 \times$ resíduo ${ }^{2}\left(R^{2}=0,96\right)$. 


\section{HEIMBACH, ÍTAVO, ÍTAVO, FRANCO, LEAL, LEAL, SILVA, REZENDE E SILVA}

$8,34 \mathrm{~g} / \mathrm{kg}$. Não houve diferença significativa para o tempo de colonização pelas bactérias ruminais em ovinos, nos diferentes níveis de inclusão do resíduo da extração de própolis marrom, sendo em média 6,35 horas e a taxa de degradação da fração rápida em média de $0,90 \%$ /hora. Conforme aumentou-se o nível de inclusão do resíduo da extração de própolis marrom, diminuiu a produção de gás da fração lenta. Entretanto, Santos et al. (2003), estimando a degradabilidade ruminal de alimentos, utilizando a técnica de produção de gás em bovinos, ovinos e caprinos, concluíram que não há diferença na produção de gás das diferentes espécies, com exceção da degradação de fibra em detergente neutro que é menor.

Silva (2011) analisando a produção de gás e digestibilidade in vitro de dietas contendo própolis marrom como aditivo, não encontrou influência da inclusão dos diferentes níveis de própolis bruta e extrato, para os parâmetros $\mathrm{A}, \mathrm{B}, \mathrm{D}, \mathrm{E}$ e $\mathrm{A}+\mathrm{D}$ da cinética de degradação, com exceção da diminuição do lag time, com a inclusão de 14,5 g/kg MS de própolis bruta e 1,96, 11,94 e $19,91 \mathrm{~mL} / \mathrm{kg}$ MS de extrato de própolis.

Groot et al. (1996), estudando a análise multifásica da cinética de produção de gás pela fermentação in vitro de ruminantes,

\section{BIBLIOGRAFIA}

AOAC. 2000. Association Official Analytical Chemists. Official Methods of Analysis of AOAC International, $17^{\text {th }}$. Gaithersburg, MD. USA.

Esteves, C.A.T. 2012. Resíduo da extração da própolis marrom na alimentação de ovinos em confinamento. Dissertação (Mestrado em Zootecnia). Universidade Federal de Mato Grosso do Sul. Campo Grande. 75 pp.

Funari, C.S. e Ferro, V.O. 2006. Análises de própolis. Cienc Tecnol Aliment, 26: 171-178.

Goering, H.K. and Van Soest, P.J. 1970. Forage Fiber Analysis (apparatus, reagents, procedures and some applications). Agricultural Handbook, 379. USDA. Washington DC. pp. 20. afirmaram que as cinéticas de produção de gás são dependentes de uma sequência de processos. Em incubação, substratos são parcialmente solubilizados, e os substratos e seus componentes podem ser resistentes a diferentes processos de degradação, resultando em perfis de produção de gás diferentes. Dessa maneira, há a necessidade de estudos para identificar a composição desses gases produzidos, pois será determinante na definição da capacidade de aproveitamento pelo animal.

O resíduo da extração de própolis marrom apresentou efeito sobre a digestibilidade ruminal in vitro da matéria seca e fibra em detergente neutro, e a digestibilidade total in vitro também apresentou diferença significativa para digestibilidade da matéria seca, proteína bruta, fibra em detergente neutro, fibra em detergente ácido. Sendo o melhor nível de inclusão para digestibilidade total in vitro de $13,88 \mathrm{~g}$ de resíduo do extrato de própolis/kg MS, respectivamente.

O melhor nível de inclusão do resíduo da extração de própolis marrom para bovinos foi $8,52 \mathrm{~g} / \mathrm{kg}$ MS e para ovinos foi $5,53 \mathrm{~g} / \mathrm{kg}$ MS, em função da produção de gás in vitro.

Mais pesquisas são necessárias para estudar a composição desses gases gerados, para que se saiba o real efeito dos mesmos, para os animais e meio ambiente. 


\section{RESÍDUO DA EXTRAÇÃO DE PRÓPOLIS MARROM NA DIETA DE RUMINANTES}

diet: Behavior and productivity of lambs in feedlot. Anim Feed Sci Technol, 165: 161-166.

Lana, R.P.; Camardelli, M.M.L.; Rodrigues, M.T.; Eifert, E.C.; Miranda, E.N. e Almeida, I.C.C. 2007. Óleo de soja e própolis na alimentação de cabras leiteiras: consume de material seca e de nutrients e parâmetros de fermentação ruminal. Rev Bras Zootecn, 36: 191-197.

Mirzoeva, O.K.; Grishanin, R.N. and Calder, P.C. 1997. Antimicrobial action of propolis and some of its components: the effects on growth, membrane potential and motility of bacteria. Microbiol Res, 152: 239-246.

Pell, A.N. and Schofield, P. 1994. Computerized monitoring of gas production to measure forage digestion in vitro. J Dairy Sci, 76: 1063-1073.

Prado, O.P.P.;Zeoula, L.M.; Pontara, L.P.M.; Franco, S.L.; Novello, C.R. e Geron, L.J.V. 2010. Adição de própolis ou monensina sódica sobre digestibilidade in vitro da matéria seca. Rev Bras Saúde Prod Anim, 11: 1023-1032.

Russell, J.B. and Strobel, H.J. 1989. Mini-Review: Effect of ionophores on ruminal fermentation. Appl Environ Microbiol, 55: 573-581.

Santos, R.A.; Teixeira, J.C.; Pérez, J.R.O.; Paiva, P.C.A.; Muniz, J.A. e Arcuri, P.B. 2003. Estimativa da degradabilidade ruminal de alimentos utilizando a técnica de produção de gás em bovinos, ovinos e caprinos. Ciênc Agrotec, 27: 689-695.

Schofield, P.; Pitt, R.E. and Pell, A.N. 1994. Kinetics of fiber digestion from in vitro gás production. J Anim Sci, 72: 2980-2991.

Silva, J.A. 2011. Própolis marrom como aditivio na alimentação de ovinos em confinamento. Dissertação (Mestrado em Zootecnia). Universidade Federal de Mato Grosso do Sul. Campo Grande. 100 pp.

Silva, J.F.C. e Leão, M.I. 1979. Fundamentos de Nutrição dos Ruminantes. E. Livroceres. Piracicaba. 384 pp.

Stelzer, F.S.; Lana, R.P.; Campos, J.M.S.; Mancio, A.B.; Pereira, J.C. e Lima, J.G. 2009. Desempenho de vacas leiteiras recebendo concentrado em diferentes níveis, associado ou não a própolis. Rev Bras Zootecn, 38: 1381-1389.

Stradiotti Jr., D.; Queiroz, A.C.; Lana, R.P.; Pacheco, C.G.; Camardelli, M.M.L.; Detmann, E.; Eifert, E.C.; Nunes, P.M.M. e Oliveira, M.V.M. 2004a. Ação do extrato de própolis sobre a fermentação in vitro de diferentes alimentos pela técnica de produção de gases. Rev Bras Zootecn, 33: 1093-1099.

Stradiotti Jr., D.; Queiroz, A.C.; Lana, R.P.; Pacheco, C.G.; Eifert, E.C. e Nunes, P.M.M. 2004b. Ação da própolis sobre a desaminação de aminoácidos e a fermentação ruminal. Rev Bras Zootecn, 33: 1086-1092.

Tilley, J.M.A. and Terry, R.A. 1963. A two stage technique for the in vitro digestion of forage crops. J British Grassland Society, 18: 104111. 